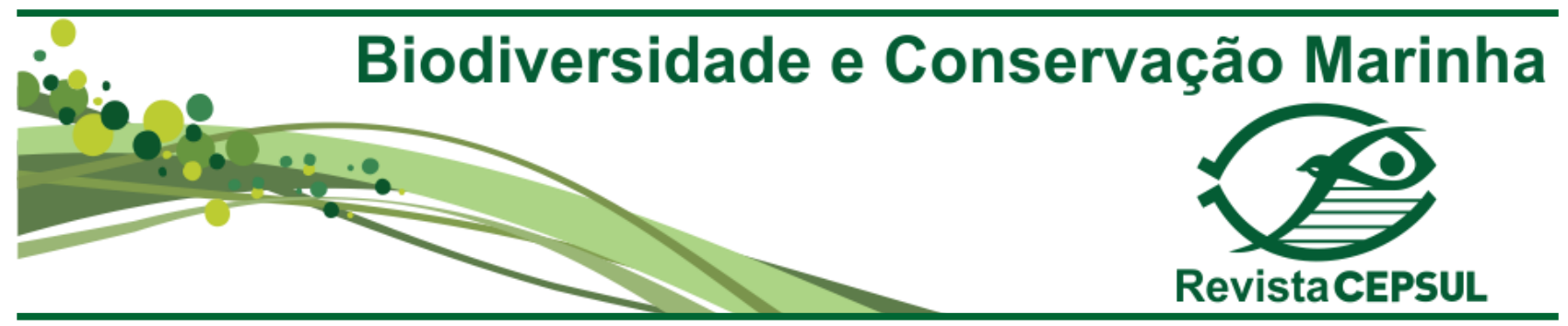

ARTIGO DE REVISÃO-ESPECIAL BABITONGA

\title{
Carcinofauna de importância econômica no Ecossistema
}

\section{Babitonga: revisão sistemática}

\author{
JenYfFer Vierheller Vieira ${ }^{1}$, Fabiano Grecco de CARVAlho² \& Alessandra Pfuetzenreuter ${ }^{2}$ \\ ${ }^{1}$ Universidade da Região de Joinville - UNIVILLE, Unidade São Francisco do Sul, Rodovia Duque de Caxias, 6365, Iperoba, CEP - \\ 89249-ooo, São Francisco do Sul, SC, Brasil, jenyffervvieira@gmail.com; \\ ${ }_{2}^{2}$ Projeto Babitonga Ativa, Universidade da Região de Joinville - UNIVILLE, Unidade São F. do Sul, Rodovia Duque de Caxias, 6365 , \\ Iperoba, CEP - 89249-ooo, São F. do Sul, SC , Brasil, fabianogreccodecarvalho@gmail.com; ale_pfuetzenreuter@hotmail.com.
}

\section{Submetido em: 16/o6/2017; Aceito em: 31/o1/2018; Publicado em: 16/10/2018}

\begin{abstract}
Resumo. O estado da arte dos estudos sobre a carcinofauna economicamente relevante para o Ecossistema Babitonga (EB) foi analisado a partir da compilação dos estudos publicados até o ano de 2016. No total foram compilados 21 trabalhos, incluindo periódicos científi$\cos (57 \%)$, literatura cinza (33\%) e livro (10\%). O texto sintetiza o atual conhecimento sobre as espécies de siris (Callinectes danae e C. sapidus), caranguejo-uçá (Ucides cordatus) e seis espécies de camarão (Artemesia longinaris, Farfantepenaeus brasiliensis, F. paulensis, Litopenaeus schmitti, Pleoticus muelleri, Xiphopenaeus kroyeri), destacando aspectos bioecológicos, socioeconômicos, ameaças naturais e antrópicas bem como instrumentos para a gestão destes recursos pesqueiros. Espera-se que esta revisão forneça subsídios que contribuam com o direcionamento de estudos futuros, buscando a boa gestão destes recursos no Ecossistema Babitonga.
\end{abstract}

Palavras-chave: cienciometria; siris; caranguejo-uçá; camarões; ecossistemas costeiros; sul do Brasil.

\begin{abstract}
Economic relevant crustaceans of Babitonga Ecosystem: systematic review. The state of the art of the studies on economically relevant crustaceans for the Babitonga Ecosystem (EB) was analyzed from the compilation of studies published until the year 2016. A total of 21 studies were recorded, including articles from indexed scientific journals (57\%), grey literature (33\%) and books (10\%). The text synthesizes the current knowledge about the swimming crabs (Callinectes danae e C. sapidus), mangrove crab (Ucides cordatus) and shrimps (Artemesia longinaris, Farfantepenaeus brasiliensis, F. paulensis, Litopenaeus schmitti, Pleoticus muelleri, Xiphopenaeus kroyeri), highlighting bioecological, socio-economic, natural and anthropic threats as well as instruments for the management of these fishing resources. It is hoped that this review will provide subsidies that contribute to the direction of future studies, aiming at the good management of these resources in the Babitonga Ecosystem.
\end{abstract}

Keywords: scientometrics, swimming crabs, mangrove crab, shrimps, coastal ecosystems, south of Brazil. 


\section{Introdução}

Decapoda (Gr. Deka, dez, + podos, pés = dez pés) é a maior Ordem dentro do Subfilo Crustacea, com aproximadamente 14.756 espécies pertencentes a 2.725 gêneros (De Grave et al., 2009). Representantes desta Ordem apresentam grande plasticidade fenotípica e ecológica e inclui os animais popularmente conhecidos como lagostins, lagostas, camarões, caranguejos e siris (Ruppert et al., 2005).

A maioria dos decápodes apresenta pelo menos duas fases de vida: planctônica (durante o estágio larval = zooplâncton) e bentônica (quando adultos) (Marafon-Almeida, 2009). O tipo e o número de estágios larvais variam amplamente entre as espécies. As larvas diferem dos adultos bentônicos, principalmente em termos de locomoção e alimentação, o que evita a competição intraespecífica e contribui para a dispersão das espécies (Pereira \& Soares-Gomes, 2002).

Estuários e baías são conhecidos como importantes locais de refúgio, desova, recrutamento e criadouro para várias espécies de invertebrados marinhos (Odum, 1983). No presente documento serão consideradas informações acerca do território denominado Ecossistema Babitonga - EB, localizado no litoral norte catarinense (Figura 1), o qual abrange o complexo estuarino da Baía Babitonga bem como a região costeira adjacente (ver artigo editorial nesse volume). Em particular, a Baía Babitonga é considerada área prioritária para a conservação com prioridade de ação e importância biológica extremamente altas (MMA, 2007).

Na fase adulta, siris, caranguejos e camarões se destacam como importantes recursos pesqueiros, alvo direto das frotas artesanal e industrial atuantes no EB. Também são importantes para a subsistência, servindo como fonte de alimento para algumas comunidades (Serafini, 2012). Além da importância socioeconômica tais crustáceos são um elo fundamental na cadeia trófica estuarina, uma vez que suas larvas representam a conexão entre produtores primários e os níveis tróficos mais elevados (Marafon-Almeida, 2009).
Levando em consideração a grande diversidade da ordem Decapoda, nesta revisão serão tratadas apenas as espécies de crustáceos de interesse econômico no Ecossistema Babitonga representadas pelos siris Callinectes $d a-$ nae Smith, 1869 e C. sapidus Rathbun, 1896, o caranguejo-uçá Ucides cordatus Linnaeus, 1763 e seis espécies de camarão: rosa (Farfantepenaeus brasiliensis Latreille, $1817 \mathrm{e}$ F. paulensis Pérez-Farfante, 1967), branco (Litopenaeus schmitti Burkenroad, 1936), setebarbas (Xiphopenaeus kroyeri Heller, 1862), barba-ruça (Artemesia longinaris Bate, 1888) e vermelho (Pleoticus muelleri Bate, 1888).

Apesar da relevância ecológica e econômica destes recursos para as comunidades pesqueiras dos municípios do entorno do EB (Araquari, Barra do Sul, Garuva, Itapoá, Joinville e São Francisco do Sul), informações bioecológicas básicas encontram-se dispersas. Uma parcela considerável deste conhecimento, ainda não publicada, permanece como literatura cinza (monografias, dissertações e teses). Diante da evidente necessidade de organização e sistematização deste conhecimento, a presente revisão foi elaborada a partir da compilação de todas as informações disponíveis sobre a carcinofauna de interesse econômico no Ecossistema Babitonga, com vistas a contribuir com a gestão pesqueira e a conservação destas espécies.

\section{Metodologia}

Para esta revisão sistemática foram considerados trabalhos acadêmicos ou literatura cinza (monografias, dissertações e teses), periódicos científicos nacionais e internacionais e capítulos de livro. Resumos indexados em anais de eventos científicos (congresso, simpósio, workshop, etc.) bem como estudos e relatórios de impacto ambiental (EIA/RIMA) não foram incluídos.

Complementarmente às buscas realizadas pelo Diagnóstico Socioambiental do Ecossistema Babitonga (Babitonga Ativa, 2017), buscamos a seguinte combinação de palavraschave (em português e inglês) "camarão+ Babi- 


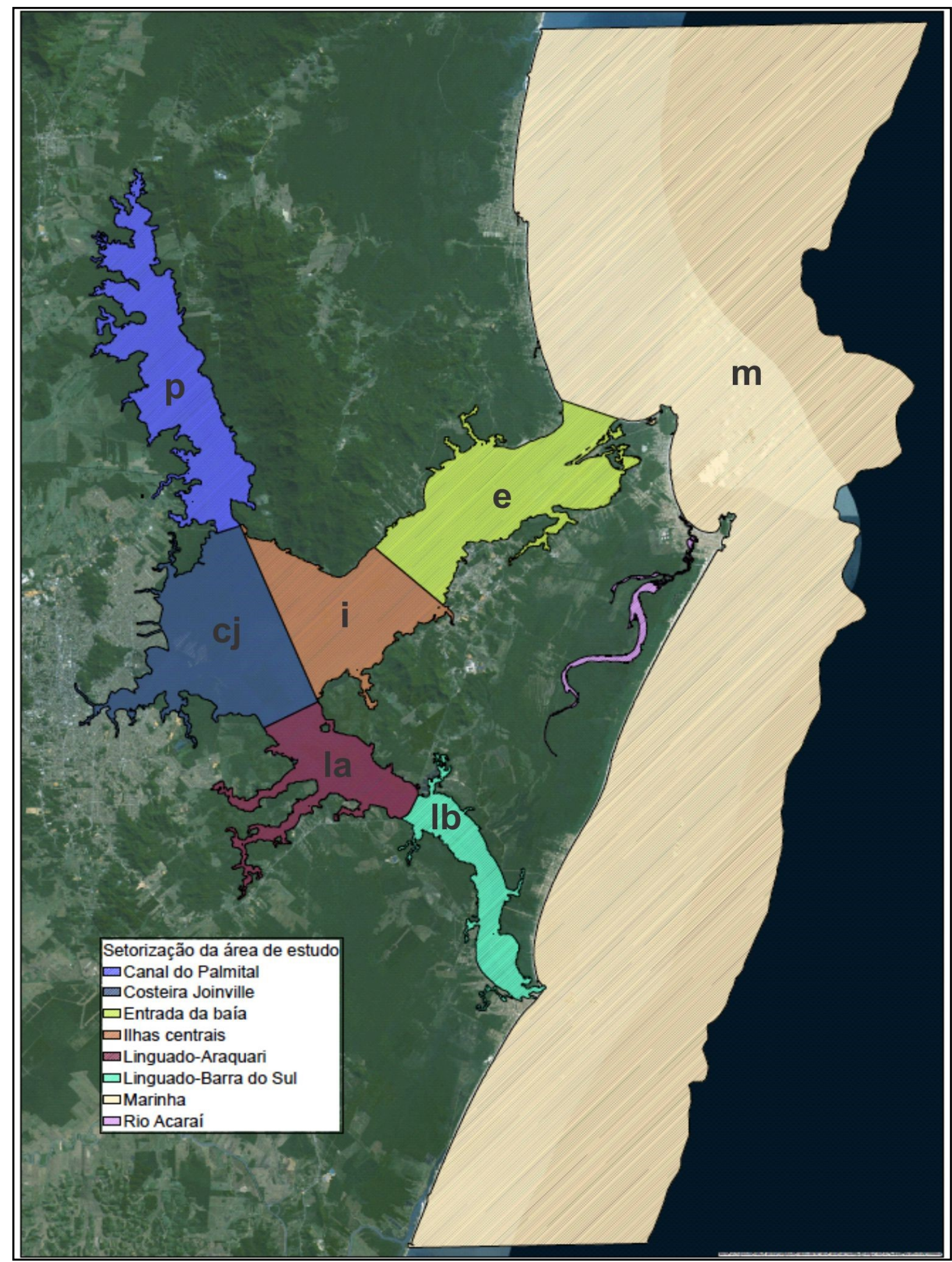

Figura 1. O Ecossistema Babitonga (EB) é compreendido pela lâmina d'água da Baía Babitonga $\left(177,3 \mathrm{okm}^{2}\right)$ até os limites de ocorrência de vegetação de manguezal $\left(81,79 \mathrm{~km}^{2}\right)$ à montante. Já na porção costeira o EB considera uma área de $856,19 \mathrm{~km}^{2}$ que se estende da barra da Baía Babitonga até a isóbata de $20 \mathrm{~m}$ ao leste, numa faixa entre a foz do rio Saí-Guaçú, em Itapoá (ao norte) e a foz do rio Itapocú, em Araquari, ao sul. Legenda das unidades de planejamento: e= Entrada da Baía; $p=$ Palmital, $c j=$ Costeira de Joinville; la= Linguado-Araquari; lb= Linguado-Barra do Sul; $\mathrm{m}=$ Marinha; $\mathrm{i}=$ Ilhas Centrais. Adaptado de Babitonga Ativa, 2017. 
tonga", "caranguejo+Babitonga", "siri+Babitonga", em seis plataformas virtuais: Science direct; Scielo; Web of Science; Web of knowledge; Scopus; Google acadêmico (entre janeiro e outubro de 2017). Também foram buscadas referências citadas nos artigos selecionados. Por se tratarem de espécies consideradas recursos pesqueiros, também foram considerados instrumentos legais (instruções normativas, portarias) e outros documentos técnicos (planos nacionais de uso sustentável e relatórios).

Primeiramente, os trabalhos selecionados foram classificados de acordo com: 1) tipo da publicação (literatura cinza, periódico científico, livro, instrumentos legais, documentos técnicos); 2) ano da publicação; 3) instituições envolvidas; 4) frequência temporal da amostragem. Tendo em vista que a maioria dos trabalhos não disponibilizou as coordenadas geográficas dos pontos de amostragem, a análise espacial dos mesmos foi realizada através da comparação visual entre os mapas fornecidos em cada estudo e o mapa referente à delimitação das Unidades de Planejamento (UP) proposto no Diagnóstico Socioambiental do Ecossistema Babitonga (Babitonga Ativa, 2017) (Figura 1). Para facilitar a organização das informações, os trabalhos contemplados nesta revisão foram agrupados de acordo com o grupo de espécies analisadas em: 1) Siris, 2) Caranguejo-uçá e 3) Camarões.

\section{Resultados e discussão}

No total foram compilados 21 trabalhos acadêmicos, sendo que $57 \%$ correspondem a periódicos científicos, seguido de literatura cinza (33\%) e livro (10\%) (Tabela 1). Dos estudos analisados, $48 \%$ abordaram os camarões, $29 \%$ siris e apenas $5 \%$ o caranguejo-uçá. Os demais trabalhos (19\%) consideraram mais de um grupo (Tabela 1). Foram também identificados seis instrumentos legais (três portarias e três instruções normativas) e cinco documentos técnicos relacionados às espécies alvo desta revisão (Tabela 2).

Estudos sobre a carcinofauna de importância comercial no EB foram conduzidos ao longo de um período de quase 20 anos, sendo o primeiro trabalho realizado pelo CEPSUL, em parceria com pesquisadores da região, e publicado em 1998 (Tabela 1). Apesar disso, 90\% dos estudos foram desenvolvidos depois de 2005 (Figura 2). Tal fato provavelmente está relacionado ao surgimento do curso de Biologia Marinha na Unidade São Francisco do Sul da UNIVILLE (Universidade da Região de Joinville) no ano de 2004. Cabe destacar aqui a importância do CEPSUL, envolvido em 38\% dos estudos, bem como da UNIVILLE (33\%) e UNESP (29\%) (Tabela 1). Parcerias institucionais foram fundamentais para o incremento da ciência no EB resultando no desenvolvimento de cinco projetos de pesquisa e extensão com ênfase nos crustáceos explorados no EB (Tabela 3).

Investigações incluindo coleta de dados biológicos com replicação mensal (perfazendo 12 meses de amostragem) foram os casos mais frequentes (55\%), enquanto que $25 \%$ corresponderam a trabalhos pontuais, ou seja, sem replicação temporal. Apenas 20\% dos estudos analisados contemplaram escala temporal com amostragens trimestrais (10\%) ou semestrais (10\%). Nenhum trabalho apresentou duração superior a 2 ou 3 anos (Tabela 4).

Siris explotados no Ecossistema

\section{Babitonga}

Decápodes pertencentes à família Portunidae são popularmente conhecidos como siris. Estes organismos possuem o último par de pereiópodos achatado dorso-ventralmente em forma de remo, facilitando a natação e o deslocamento (Pinheiro et al., 2016).

Todos os portunídeos do gênero Callinectes podem ser utilizados como alimento pelos humanos, contudo no Ecossistema Babitonga apenas $C$. danae e $C$. sapidus são explotadas para fins comerciais e/ou subsistência. Em 2008, aproximadamente 20 famílias direcionavam sua atividade pesqueira aos siris dentro da Baía Babitonga, algumas vivendo exclusivamente dessa atividade (Costa et al., 2008).

Em conjunto, as pesquisas que avalia- 
ram espécies do gênero Callinectes no EB contemplaram todas as unidades de planejamento, com exceção da UP Acaraí (Tabela 4). Cabe destacar que o trabalho pioneiro, desenvolvido por Branco (1998), incluiu um vasto número de pontos amostrais representados por seis UP's. Apesar desta representativa abordagem espacial, não houve replicação temporal satisfatória (Tabela 4).

Tabela 1. Lista de trabalhos sobre siris (a), caranguejo (b) e camarões (c) de importância econômica realizados no Ecossistema Babitonga, com destaque ao tipo (literatura cinza, periódico científico e livro) e ano da publicação bem como instituições envolvidas. $\left(^{*}\right)$ estudos que analisaram dois ou mais grupos.

\begin{tabular}{|c|c|c|c|}
\hline Grupo estudado & Fonte (citação) & Tipo & Instituições Envolvidas \\
\hline \multirow{10}{*}{ (a) Siris } & Branco, 1998* & Livro & CEPSUL; IBAMA; UNIVALI \\
\hline & Leite, $2005^{*}$ & Literatura cinza - TCC & UNIVILLE; CEPSUL \\
\hline & Oliveira et al. 2006* & Livro & UNIVILLE; \\
\hline & Costa et al. 2008 & Periódico & CEPSUL \\
\hline & Pereira et al., 2009 & Periódico & UNIVALI, UFPB, UFSCAR \\
\hline & Egres et al. 2009 & Periódico & UNIVILLE; CEPSUL \\
\hline & Marafon-Almeida, 2009* & Literatura cinza - dissertação & UNIVILLE; CEPSUL \\
\hline & Sabino, 2014 & Literatura cinza - dissertação & UNESP \\
\hline & Andrade et al. 2015 & Periódico & UNESP \\
\hline & Brandão et al. $2015^{*}$ & Periódico & UFSC; FURG \\
\hline \multirow{4}{*}{ (b) Caranguejo } & Branco, 1998* & Livro & CEPSUL; IBAMA; UNIVALI \\
\hline & Oliveira et al. 2006* & Livro & UNIVILLE \\
\hline & Wunderlich et al. 2008 & Periódico & UNESP; CEPSUL \\
\hline & Marafon-Almeida, 2009* & Literatura cinza - dissertação & UNIVILLE; CEPSUL \\
\hline \multirow{14}{*}{ (c) Camarões } & Branco, 1998* & Livro & CEPSUL; IBAMA; UNIVALI \\
\hline & Leite, $2005^{*}$ & Literatura cinza - TCC & UNIVILLE; CEPSUL \\
\hline & Oliveira et al. 2006* & Livro & UNIVILLE; \\
\hline & Dumont et al. 2007 & Periódico & FURG; CEPSUL \\
\hline & Marafon-Almeida et al. 2008 & Periódico & UNIVILLE \\
\hline & Preto, 2009 & Literatura cinza - tese & UFSCAR \\
\hline & Machado et al. 2009 & Periódico & FURG \\
\hline & Grabowski, 2012 & Literatura cinza - dissertação & UNESP \\
\hline & Grabowski et al. 2014 & Periódico & UNESP \\
\hline & Wolf, 2014 & $\begin{array}{l}\text { Literatura cinza - disserta- } \\
\text { ção }\end{array}$ & UNESP \\
\hline & Schmitt, 2015 & Literatura cinza - TCC & UNIVILLE \\
\hline & Rodrigues et al. 2015 & Periódico & UNIVALI; CEPSUL \\
\hline & Brandão et al. $2015^{*}$ & Periódico & UFSC; FURG \\
\hline & Grabowski et al. 2016 & Periódico & UNESP \\
\hline
\end{tabular}


Tabela 2. Lista de instrumentos legais e outros documentos técnicos relacionados à carcinofauna de importância comercial no Ecossistema Babitonga.

\section{Instrumentos legais}

Portaria SUDEPE, $\mathrm{n}^{0} \mathrm{~N} 24 / 1983$

Portaria IBAMA n ${ }^{0} 70 / 2003$

Portaria IBAMA n ${ }^{0} 52 / 2003$

Instrução Normativa MMA n ${ }^{0}$ $005 / 2004$

Instrução Normativa IBAMA $\mathrm{n}^{0} 189 / 2008$

Instrução Normativa Interministerial MPA/MMA n⿳0 $3 / 2011$
Regulamenta a pesca do siri-azul (Callinectes danae e C. sapidus), estabelecendo o tamanho mínimo de $12 \mathrm{~cm}$ de carapaça, medido a partir da ponta dos maiores espinhos laterais

Institui o defeso do camarão-branco (Litopenaeus schmitti) e camarão-rosa (Farfantepenaeus paulensis) no interior da Baía Babitonga no período de $1^{\circ}$ de novembro a 31 de janeiro

Institui o período de defeso do caranguejo-uçá (Ucides cordatus) nos estados do Espírito Santo, Rio de Janeiro, São Paulo, Paraná e Santa Catarina no período entre $1^{\circ}$ de outubro a 30 de novembro para todos os indivíduos e no período de $1^{\circ}$ a 31 de dezembro, só para as fêmeas. Proíbe em qualquer época do ano a captura de fêmeas ovadas, indivíduos com largura da carapaça inferior a $6,0 \mathrm{~cm}$ ou partes isoladas (quelas, patas ou garras)

Lista de espécies ameaçadas de extinção e espécies sobreexplotadas ou ameaçadas de sobreexplotação, os invertebrados aquáticos e peixes

Estabelece o período de defeso dos camarões-rosa (Farfantepenaeus paulensis, $F$. brasiliensis, $F$. subtilis), camarão-sete-barbas (Xyphopenaeus kroyeri), camarão-branco (Litopenaeus schmitti), camarão-santana ou vermelho (Pleoticus muelleri) e camarão-barbarussa (Artemesia longinaris) no período de $1^{\circ}$ de março a 31 de maio entre os estados do Espírito Santo e Rio Grande do Sul

Dispõe sobre critérios e procedimentos para a concessão de Autorização de Pesca e efetivação do registro de embarcação pesqueira para operar na captura de camarão-sete-barbas, Xiphopenaeus kroyeri, no litoral sudeste/sul

\section{Documentos técnicos}

Dias-Neto, 2011a

Dias-Neto, 2011b

Boos et al. 2012

Pinheiro \& Almeida, 2015
Proposta de plano nacional de gestão para o uso sustentável do caranguejo-uçá, do guaiamum e do siri-azul

Proposta de plano nacional de gestão para o uso sustentável de camarões marinhos do Brasil

Checklist dos crustáceos do Estado de Santa Catarina

Monitoramento da população do caranguejo-uçá, Ucides cordatus (Brachyura: Ucididae)
Callinectes danae é citada como a espécie mais abundante dentre os portunídeos que habitam o EB (Costa et al., 2008; Egres et al., 2009; Pereira et al., 2009; Andrade et al., 2015). Em muitas regiões da costa brasileira $C$. danae é considerada espécie "secundária" para os pescadores artesanais, os quais capturam principalmente $C$. sapidus devido seu maior tamanho e valor de mercado (Pereira et al., 2009). Contudo, em função da sua elevada abundância na Babitonga, C. danae é reconhecido como o siri mais explorado. Há quase uma década, Costa et al. (2008) apresentaram uma estimativa, baseada na informação de pescadores locais, que aponta para uma captura mensal de 61.00o indivíduos na Baía Babitonga.

Registros da espécie $C$. danae foram documentados tanto dentro do estuário (Branco, 1998; Costa et al., 2008; Egres et al., 2009; Pereira et al., 2009) quanto na plataforma adjacente (Leite, 2005; Sabino, 2014; Andrade et al., 2015), sendo considerada a espécie de portunídeo mais eurihalina (Branco, 1998).

De modo geral, foi possível constatar que machos de $C$. danae tendem a apresentar 


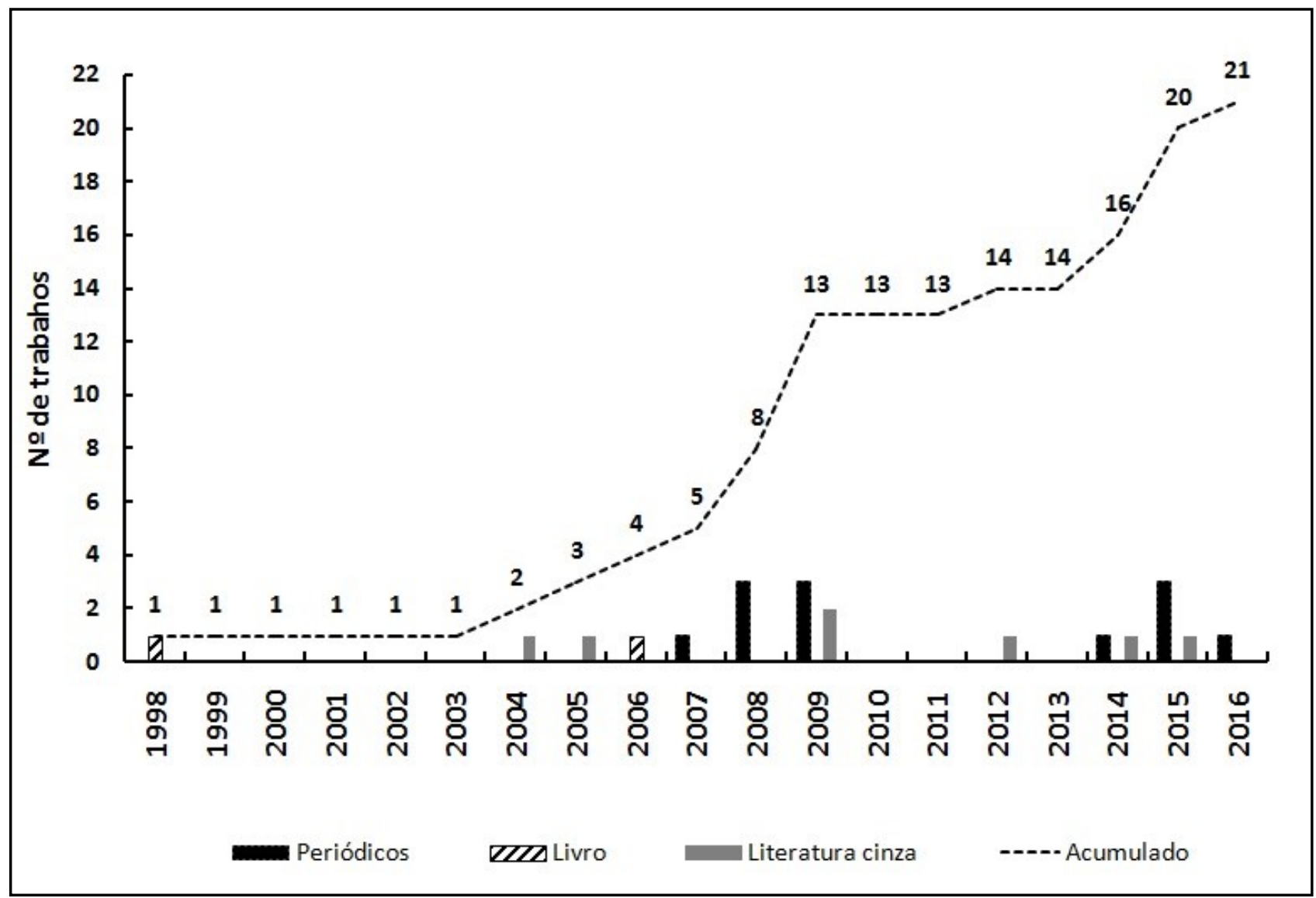

Figura 2. Evolução temporal dos trabalhos científicos sobre a carcinofauna de importância econômica no Ecossistema Babitonga.

Tabela 1. Lista dos projetos de pesquisa e extensão relacionados à carcinofauna de importância econômica no Ecossistema Babitonga desenvolvidos pela UNIVILLE em parceria com outras instituições.

\begin{tabular}{|c|c|c|}
\hline Período & Título & Instituições envolvidas \\
\hline 2002-2003 & $\begin{array}{c}\text { Bioecologia do caranguejo-uçá, Ucides cordatus } \\
\text { (Linnaeus, 1763) (Crustacea, Decapoda, Brachyura), da } \\
\text { Baía da Babitonga }\end{array}$ & $\begin{array}{l}\text { UNIVILLE/ CEPSUL/ IBAMA/ } \\
\text { UNESP }\end{array}$ \\
\hline 2004-2010 & $\begin{array}{c}\text { Levantamento e Avaliação das populações de camarões- } \\
\text { branco e rosa na Baía da Babitonga e plataforma adja- } \\
\text { cente }\end{array}$ & UNIVILLE/ CEPSUL \\
\hline 2006-2007 & $\begin{array}{l}\text { Aspectos biológicos e pesqueiros de portunídeos } \\
\text { (Crustacea, Decapoda) na Baía da Babitonga (Santa Ca- } \\
\text { tarina, Brasil) e sua relação com os parâmetros ambien- } \\
\text { tais }\end{array}$ & UNIVILLE/ CEPSUL \\
\hline $2008-2010$ & $\begin{array}{l}\text { Aspectos da biologia, ecologia e pesca de portunídeos } \\
\text { (Crustacea, Decapoda) na Baía da Babitonga (Santa Ca- } \\
\text { tarina, Brasil) e sua relação com os parâmetros ambien- } \\
\text { tais }\end{array}$ & UNIVILLE/ CEPSUL \\
\hline $2015-2016$ & $\begin{array}{l}\text { Cultivo do camarão Farfantepnaeus brasiliensis em tan- } \\
\text { ques-rede e sistema de recirculação para produção de } \\
\text { isca-viva no município de São Francisco do Sul - Santa } \\
\text { Catarina - Brasil }\end{array}$ & $\begin{array}{l}\text { UNIVILLE/ FURG / Fazenda } \\
\text { Quality Camarões }\end{array}$ \\
\hline
\end{tabular}




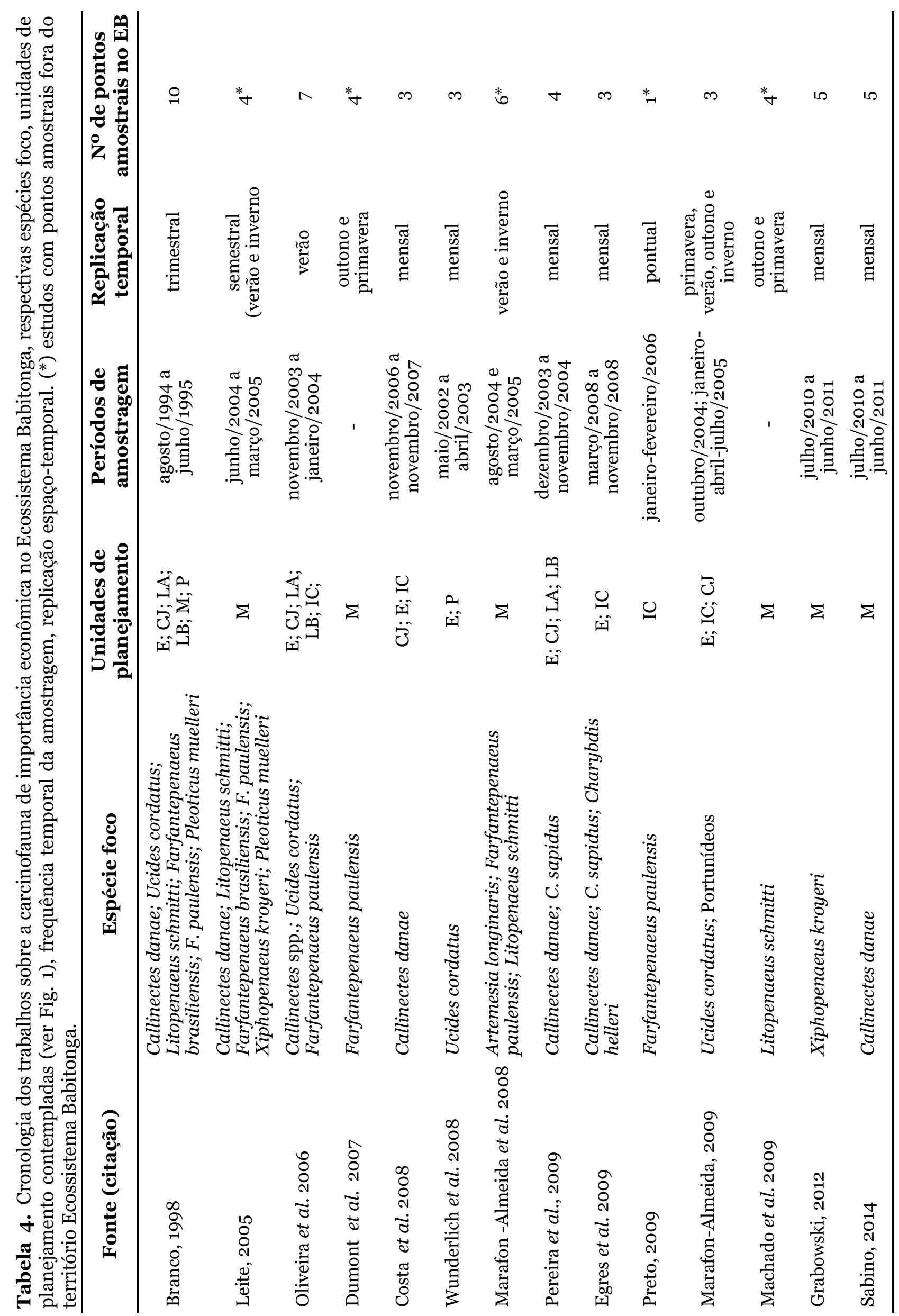




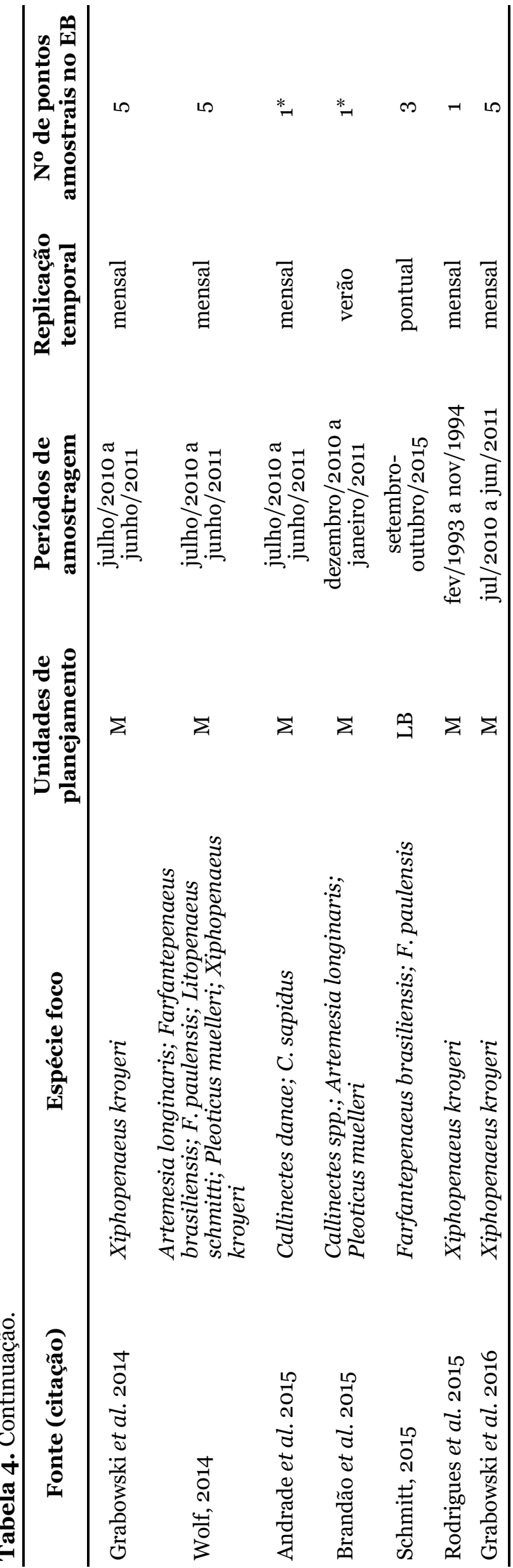

tamanho maior que as fêmeas (Tabela 5a). Ao longo da costa brasileira, existe grande variação na largura da carapaça e tamanho da primeira maturação de $C$. danae conforme a região de coleta, contudo, este padrão entre machos e fêmeas já foi relatado em diversos estudos (ver Pinheiro et al., 2016).

Dentro da Baía Babitonga foi registrada proporção sexual em favor dos machos (Costa et al., 2008; Pereira et al., 2009), enquanto na plataforma adjacente Sabino (2014) constatou elevada ocorrência de fêmeas. Tais informações corroboram a hipótese levantada por Branco (1998) e Egres et al. (2009), de que a fecundação de $C$. danae ocorre no estuário. Segundo estes autores, após a fecundação as fêmeas migram para a plataforma adjacente onde ocorre a eclosão dos ovos, enquanto os machos permanecem no estuário a maior parte do ciclo de vida (Pereira et al., 2009). Ou seja, há uma relação direta entre oviposição e águas salinas (Severino-Rodrigues et al., 2012). Por outro lado, regiões de baixa salinidade servem como áreas de crescimento (Pinheiro et al., 2016).

A espécie $C$. danae apresenta reprodução contínua, com aumento de fêmeas ovígeras no verão e machos reprodutivos na primavera e verão (Sabino, 2014). A fecundidade estimada foi de 755.357.250 ovos (Pereira et al., 2009), enquanto que a longevidade foi de 1,73 anos para machos e 1,81 anos para fêmeas (Sabino, 2014).

Callinectes danae ocorre em simpatria com C. sapidus, portanto, ambas as espécies são comercializadas como recurso pesqueiro "siri" (Dias-Neto, 2011a). Apesar disto, apenas C. sapidus consta na Lista Nacional de espécies ameaçadas de sobre-explotação do MMA (Instrução Normativa MMA $\mathrm{n}^{0} 5$, de 21 de maio de 2004 - IN MMA n ${ }^{0}$ 5/2004).

Callinectes sapidus, conhecido regionalmente como siri-azul, siri-pedra ou siripatola, é comumente registrado dentro da Baía Babitonga (Branco, 1998; Egres et al., 2009; Pereira et al., 2009). Andrade et al. (2015) foi o único trabalho que registrou a ocorrência desta espécie na plataforma adjacente (UP Ma- 
Tabela 5. Parâmetros biológicos da carcinofauna de importância comercial no EB, incluindo largura da carapaça mínimo (CC - mín) e máximo (CC - máx) e largura da carapaça onde $50 \%\left(\mathrm{LC}_{50}\right)$ das espécies de siris estão aptos à reprodução e comprimento da carapaça mínimo (CC - mín) e máximo (CC máx) e comprimento da carapaça onde $50 \%$ das espécies de camarões estão aptos à reprodução. Unidade: milímetros (mm). (-) dado inexistente.

\begin{tabular}{|c|c|c|c|c|c|c|c|c|}
\hline \multirow{2}{*}{$\begin{array}{l}\text { Grupo } \\
\text { estudado }\end{array}$} & \multirow[t]{2}{*}{ Espécie } & \multicolumn{3}{|c|}{ Machos } & \multicolumn{3}{|c|}{ Fêmeas } & \multirow[t]{2}{*}{ Fonte } \\
\hline & & $\underset{\text { (mín) }}{\text { LC }}$ & $\begin{array}{c}\text { LC } \\
\text { (máx) }\end{array}$ & $\mathbf{L C}_{50}$ & $\begin{array}{c}\text { LC } \\
\text { (mín) }\end{array}$ & $\underset{\text { (máx) }}{\text { LC }}$ & $\mathbf{L C}_{50}$ & \\
\hline \multirow{4}{*}{ (a) Siris } & C. danae & 1 & 13,6 & 8,6 & 5,1 & 11,6 & 7,1 & Pereira, 2006 \\
\hline & & 1,325 & 9,51 & 7,52 & 0,9 & 8,82 & 6,29 & Sabino, 2014 \\
\hline & C. sapidus & 6,5 & 16,2 & 9 & 5,5 & 15,3 & 10,2 & Pereira, 2006 \\
\hline & & $\underset{\text { (mín) }}{\text { CC }}$ & $\begin{array}{c}\text { CC } \\
\text { (máx) }\end{array}$ & $\mathbf{C C}_{50}$ & $\underset{\text { (mín) }}{\text { CC }}$ & $\underset{\text { (máx) }}{\text { CC }}$ & $\mathrm{CC}_{50}$ & \\
\hline \multirow{7}{*}{ (b) Camarões } & F. paulensis & 16,6 & 27,7 & - & 13,9 & 31,1 & - & Wolf, 2014 \\
\hline & F. brasiliensis & 18,2 & 26,4 & - & 19,4 & 31,8 & - & Wolf, 2014 \\
\hline & L. schmitti & 20,8 & 32,4 & 22,3 & 16,8 & 55,2 & 24,6 & Wolf, 2014 \\
\hline & & 6,0 & 28,0 & - & 6,0 & 35,0 & 19,5 & Rodrigues et al. 2015 \\
\hline & & 7,1 & 27,9 & - & 6,0 & 31,8 & - & Grabowski et al. 2014 \\
\hline & P. muelleri & 6,4 & 16,9 & 10,9 & 6,4 & 22 & 12 & Wolf, 2014 \\
\hline & A. longinaris & 9,1 & 15,3 & - & 9,1 & 19,7 & - & Wolf, 2014 \\
\hline
\end{tabular}

rinha) (Tabela 4).

Independente da região estudada no $\mathrm{EB}$, C. sapidus apresentou menores porcentagens de captura quando comparado a $C$. danae (o,6\% e 99,4\% em Egres et al., 2009; 12,6\% e 85,4\% em Pereira et al., 2009; 0,1\% e 99,9\% em Andrade et al., 2015, respectivamente). Em alguns estudos, $C$. sapidus tampouco foi capturado (Leite, 2005; Costa et al., 2008).

Aspectos da biologia populacional de $C$. sapidus dentro da Baía Babitonga foram analisados apenas por Pereira (2006). Assim como já relatado para o seu congênere ( $C$. danae), machos de $C$. sapidus atingem tamanho final maior do que as fêmeas (Tabela 5a). Quanto à proporção sexual, foi registrada a dominância de fêmeas, as quais apresentaram fecundidade média de 978.109.00o ovos (Pereira et al., 2009).
No Ecossistema Babitonga as populações de portunídeos, particularmente $C$. danae e $C$. sapidus, estão expostas a algumas ameaças, das quais merecem destaque: a pesca intencional ou não (bycatch) e a presença de espécies invasoras.

A pescaria das duas espécies ao longo de toda a costa brasileira é regulamentada pela Portaria SUDEPE n⿳0 024/19783, a qual proíbe a captura de fêmeas ovígeras e de indivíduos de ambos os sexos com largura da carapaça incluindo espinhos laterais inferior a $12 \mathrm{~cm}$. Ademais C. sapidus foi contemplado na Proposta de Plano Nacional de Gestão para o uso sustentável do caranguejo-uçá, do guaiamum e do siri-azul (Dias-Neto, 2011a). Callinectes danae não é tratada neste plano, uma vez que não foi incluída na categoria de espécies sobreexplotadas ou ameaçadas de sobre-explotação 
(IN MMA $n^{\circ}$ 5/2004). No entanto, os autores do plano sugerem que todas as medidas previstas sejam aplicáveis para ambas as espécies (Dias-Neto, 2011a).

Além da pesca intencional por meio do uso de artefatos fixos (puçá), a espécie $C$. $d a-$ nae também é capturada como fauna acompanhante (bycatch) na pescaria do camarão-setebarbas (Xiphopenaeus kroyeri) e pescarias de praias, realizadas com redes. Os crustáceos decápodes são um dos principais grupos identificados no bycatch de $X$. kroyeri, sendo $C$. danae e $C$. ornatus os portunídeos mais frequentes (Branco et al., 2015).

Em 2009, o siri exótico Charybdis hellerii (A. Milne-Edwards, 1867) foi reportado pela primeira vez no EB (Egres et al., 2009), informação corroborada no checklist de crustáceos de Santa Catarina (Boos et al., 2012). No Brasil, C. hellerii configura-se como possível competidor dos portunídeos nativos Portunus spp., Arenaeus cribrarius e Cronius ruber inclusive Callinectes spp. (Boos et al., 2010).

\section{Caranguejos explotados no Ecos-}

\section{sistema Babitonga}

Ucides cordatus (Linnaeus, 1763) é um caranguejo que ocorre apenas na região entremarés, tendo como habitat exclusivo o ambiente estuarino associado à vegetação dos manguezais (Dias-Neto, 2011a). Além das funções ecológicas desempenhadas (ver Wunderlich et al., 2008; Pinheiro et al., 2016), o caranguejouçá tem grande importância econômica (Branco, 1998), sendo a única espécie de caranguejo explorada no Ecossistema Babitonga.

Apesar da relevância ecológica e socioeconômica da espécie para o EB, existem apenas três trabalhos direcionados ao estudo de Ucides cordatus neste território (Branco, 1998; Oliveira et al., 2006 e Wunderlich et al., 2008). A espécie também é citada em um trabalho que identificou três estágios larvais de $U$. cordatus no zooplâncton dentro da Babitonga (Marafon-Almeida, 2009).

Branco (1998) analisou trimestralmente a densidade ( $\mathrm{n}^{0}$ de tocas $/ \mathrm{m}^{2}$ ) de $U$. cordatus em quatro localidades do EB: duas na UP Costeira de Joinville (Ilha do Mel e Joinville), uma na UP Canal do Linguado Araquari e uma na porção inferior da UP Palmital (rio Cubatão Pequeno), sendo neste último local registrada a maior densidade média (oscilando entre 2,3 e 4,1 tocas $/ \mathrm{m}^{2}$ ). Por usa vez, as menores densidades foram constatadas em Joinville, variando entre 1,4 e 3,8 tocas $/ \mathrm{m}^{2}$.

Passada uma década, Wunderlich et al. (2008) comparou, mensalmente, a densidade de tocas do manguezal presente na porção intermediária da UP Palmital e na UP Entrada da Baía Babitonga (rio Monte de trigo, localidade Iperoba), não detectando diferença significativa na densidade de $U$. cordatus entre os pontos amostrais.

Levando em consideração a qualidade ambiental da UP Palmital relatada por diversos autores (ver Branco, 1998; Cremer et al., 2006), bem como, a similaridade na densidade de caranguejos entre os manguezais do Palmital e do Iperoba (Wunderlich et al., 2008), torna-se evidente a necessidade de conservação dos manguezais às margens do rio Palmital e Monte de Trigo (Iperoba) para a manutenção da população de Ucides cordatus no EB.

Machos com gônadas maturas ocorreram durante todo o ano, com maiores incidências na primavera (38\%) e verão ( $25 \%)$, enquanto que, fêmeas com gônadas maturas foram registradas apenas de novembro a março (primavera $81 \%$ e verão $19 \%$ ) com picos em novembro $(95,2 \%)$ e fevereiro $(18,2 \%)$ (Wunderlich et al., 2008).

Estes autores também determinaram o período de cópula das fêmeas, com espermatecas turgidas registradas em todo o período de amostragem. No entanto, fêmeas ovígeras foram observadas somente em dezembro $(35,1 \%)$ e janeiro (6,5\%), indicando a sazonalidade da reprodução, a qual está associada com o aumento do fotoperíodo e da precipitação (Wunderlich et al., 2008).

O comportamento da "andada" está intimamente relacionado ao período de acasalamento da espécie, com maiores incidências 
deste fenômeno no EB documentadas nos meses de dezembro e janeiro (Wunderlich et al., 2008). Tais informações sugerem que neste território a fase reprodutiva do caranguejo-uçá ocorre dentro do período de defeso estabelecido para a espécie (Tabela 2).

Contudo, Serafini (2012) cita o verão como o período de maior comercialização deste recurso no EB, devido à intensa movimentação de turistas na região.

No Ecossistema Babitonga o caranguejo-uçá é explorado para fins comerciais em 14 localidades (Branco, 1998). Bastos (2006) aponta $U$. cordatus como uma das espécies mais importantes para a pesca artesanal na Baía Babitonga, considerando-o como o principal recurso pesqueiro em Araquari. Em adição, Serafini (2012) considera que o caranguejo assume maior importância econômica nas localidades do Morro do Amaral e Vigorelli (Joinville) e Barrancos (Garuva).

Com base na densidade de tocas com diâmetro de abertura superior a 4,5 cm, Wunderlich et al. (2008) estimaram em 74\% o Potencial Extrativo Imediato do caranguejo-uçá. Além da incidência da pescaria artesanal, a captura realizada por pessoas que não são pescadoras e/ou que utilizam métodos ilegais tais como a "redinha" são destacados como outros importantes vetores de pressão sobre o estoque do caranguejo-uçá no EB. O emprego da "redinha" não seleciona o tamanho dos caranguejos, e quando abandonado nos manguezais atua como artefato de pesca fantasma (Serafini, 2012).

O trabalho desenvolvido por Oliveira et al. (2006) é de grande relevância, uma vez que analisou a presença de contaminantes no músculo de caranguejos oriundos do EB. Tais autores detectaram a presença de zinco em concentrações superiores àquela permitida pela legislação brasileira para alimentos provenientes do mar (3 a $30 \mathrm{ppm}$ ) nas localidades do Linguado $(55,89 \mathrm{mg} / \mathrm{kg})$, Barra do Sul $(51,40 \mathrm{mg} / \mathrm{kg})$, Saguaçú $(58,75 \mathrm{mg} / \mathrm{kg})$ e Vigorelli $(54,67 \mathrm{mg} /$ $\mathrm{kg})$.

Camarões explotados no Ecossis-

\section{tema Babitonga}

Ao longo da costa brasileira, camarões marinhos costeiros de importância econômica pertencem basicamente a duas famílias: Penaeidae e Solenoceridae (Dias-Neto, 2011b). A família Penaeidae inclui os camarões mais capturados pela pesca e com maior valor comercial no país (Boos et al, 2016). De acordo com o checklist dos crustáceos de Santa Catarina (Boos et al., 2012), camarões peneídeos de importância comercial são representados por cinco espécies (Artemesia longinaris Bate, 1888; Farfantepenaeus brasiliensis Latreille, 1817; F. paulensis Pérez-Farfante, 1967; Litopenaeus schmitti Burkenroad, 1936; Xiphopenaeus kroyeri Heller, 1862), enquanto, que camarões solenocerídeos são representados por uma única espécie, Pleoticus muelleri Bate, 1888. No Ecossistema Babitonga há registro de todas as espécies supracitadas (Wolf, 2014).

Dentre as espécies de camarão exploradas no EB $(\mathrm{N}=6)$ apenas o camarão-barba-ruça (A. longinaris) e o camarão-santana ( $P$. muelleri) não foram incluídos na Lista Nacional de Espécies de Invertebrados Aquáticos e Peixes Sobre-Explotados ou Ameaçados de SobreExplotação (IN MMA n ${ }^{0}$ 5/2004).

Os recursos pesqueiros camarão-rosa (F. brasiliensis e F. paulensis) e camarãobranco (L. schmitti) vivem dentro do estuário na fase juvenil e na plataforma adjacente quando adultos (ver Boos et al., 2016), sendo as regiões estuarinas reconhecidas como verdadeiros berçários destas espécies.

A maioria dos estudos que analisaram espécies de camarão-rosa presentes no EB $(\mathrm{N}=8)$ foi conduzido na plataforma adjacente, ou seja, UP Marinha (Tabela 4).

Dentro do estuário, $F$. paulensis foi registrado por Branco (1998) e Preto (2009), enquanto que $F$. brasiliensis é citado apenas por Schmitt (2015). Branco (1998) destaca que a ausência de $F$. brasiliensis no seu estudo provavelmente está relacionada ao reduzido número de amostragens (escala temporal).

Análises morfométricas e de microssatélites constataram a possível existência de 
quatro populações de $F$. paulensis no sulsudeste do Brasil, sendo uma delas associada à Baía Babitonga (Preto, 2009). Segundo o autor, tal heterogeneidade pode ser explicada pela hipótese do recrutamento por retroalimentação. Assim, adultos (hábito sedentário) da plataforma continental forneceriam pós-larvas, as quais recrutariam preferencialmente em um estuário próximo, que ao final do ciclo, forneceriam sub-adultos para áreas da plataforma continental mais próximas.

A megafauna, incluindo os camarões, da plataforma adjacente ao EB foi estudada por Leite (2005), sendo os maiores valores de densidade e biomassa de $F$. paulensis e $F$. brasiliensis obtidos nas profundidades de 40 e $60 \mathrm{~m}$ (fora do território $\mathrm{EB}$, que vai até a isóbata de 20m). Recentemente, a distribuição espaçotemporal da assembleia de camarões na UP Marinha do EB (entre 5 e $17 \mathrm{~m}$ ) foi analisada por Wolf (2014). Espacialmente, a maior representatividade de $F$. paulensis e $F$. brasiliensis foi registrada nas profundidades entre 14 e 17 $\mathrm{m}$, havendo predomínio de indivíduos juvenis e rudimentares, de ambos os sexos. Apesar de Leite (2005) não avaliar a biometria dos camarões, provavelmente os indivíduos juvenis coletados por Wolf (2014) estavam migrando do estuário em direção às áreas mais profundas da costa, ocupadas pelo estrato adulto destas populações.

Wolf (2014) ainda cita que fêmeas de ambas as espécies apresentam comprimento de carapaça (CC) maior do que os machos (Tabela 5b). Nas análises temporais foi possível observar que a maior abundância dos juvenis ocorreu durante o verão: de janeiro a março para $F$. paulensis, e em fevereiro para $F$. brasiliensis. Tal fato indica que o verão corresponde ao período de recrutamento destas espécies.

Fases larvais de $F$. paulensis foram encontradas na plataforma adjacente à desembocadura do canal da Barra do Sul e do rio SaíGuaçu (divisa entre o estado de SC e PR), a 20 $\mathrm{m}$ de profundidade, particularmente no verão (Marafon-Almeida et al., 2008). Não existe literatura disponível a respeito dos estágios larvais de $F$. brasiliensis no EB.
No Ecossistema Babitonga, o trabalho de Branco (1998) foi o único a registrar o camarão-branco (Litopenaeus schmitti) no interior da Babitonga nas UPs "Entrada da Baía", "Linguado-Araquari" e "Linguado-Barra do Sul". Os demais estudos constataram a ocorrência de adultos (Leite, 2005; Machado et al., 2009; Wolf, 2014) e larvas (Marafon-Almeida, 2009) na UP Marinha.

Parâmetros do ciclo de vida do camarão -branco tais como o CC e comprimento da carapaça na primeira maturação sexual ( $\mathrm{CC}_{50} \mathrm{O}$ foram investigados por Wolf (2014) (Tabela 5c). De acordo com Machado et al. (2009) a menor fêmea madura de $L$. schmitti apresentou $152 \mathrm{~mm}$ de comprimento total, sendo que com $170 \mathrm{~mm}$ todas as fêmeas estavam maduras.

Indivíduos desta espécie (L. schmitti) já foram encontrados nas profundidades de 5,8 , 11, 14 e 17 m, com maior abundância absoluta, composta principalmente por juvenis e fêmeas adultas, constatada aos $5 \mathrm{~m}$ em associação ao camarão-sete-barbas (Wolf, 2014). Leite (2005), por sua vez, não encontrou a espécie em profundidades maiores a $20 \mathrm{~m}$.

Com relação à distribuição temporal, Wolf (2014) indica os meses de fevereiro, março e abril como aqueles com as maiores densidades da espécie. De acordo com MarafonAlmeida (2009), a presença de larvas no período de verão é um indicativo da atividade reprodutiva da espécie. O verão também foi o período com o maior número de registros de fêmeas adultas, sendo a maior proporção de adultas reprodutivas evidenciada aos $17 \mathrm{~m}$ (Wolf, 2014). O mesmo autor ainda observou uma predominância de fêmeas na população, em razão de 1,54 fêmeas para cada macho.

Diferentemente do camarão-rosa e do camarão-branco, as outras espécies de camarões de importância econômica no $\mathrm{EB}$, tais como o sete-barbas (Xiphopenaeus kroyeri), barba-ruça (Artemesia longinaris) e santana (Pleoticus muelleri) não dependem do ambiente estuarino ao longo do seu ciclo de vida (ver Boos et al., 2016).

Dentre estas espécies, Xiphopenaeus 
kroyeri (sete-barbas) é a espécie dominante, considerada determinante na assembleia de camarões da plataforma adjacente da Baía Babitonga (Wolf, 2014). Existem quatro estudos direcionados à bioecologia de $X$. kroyeri no EB (Grabowski et al., 2012; Grabowski et al., 2014; Grabowski et al., 2016; Rodrigues et al., 2015) (Tabela 4). Todos estes estudos foram desenvolvidos na Unidade de Planejamento Marinha, no entanto, em dois pontos amostrais distintos, um na porção norte, defronte à costa de Itapoá (Wolf, 2014; Grabowski et al., 2014; Grabowski et al., 2016) e o outro na porção sul, na costa de Balneário Barra do Sul (Rodrigues et al., 2015).

Seguindo o padrão das espécies supracitadas, fêmeas de X. kroyeri apresentam CC maior quando comparadas aos machos (Tabela 5b). Grabowski et al. (2014) observaram que a longevidade também varia de acordo com o sexo, sendo que fêmeas atingem 1,81 anos (661 dias) e machos 1,71 anos (538 dias).

Analisando o $\mathrm{CC}_{50}$ (Tabela 5b) bem como a distribuição mensal dos valores de CC apresentados por fêmeas de X. kroyeri, Rodrigues et al. (2015) concluíram que a atividade pesqueira captura, na maior parte do ano, fêmeas que ainda não atingiram a maturidade sexual.

Xiphopenaeus kroyeri foi a espécie dominante em todas as profundidades amostradas $(5,8,11,14$ e $17 \mathrm{~m})$ por Wolf (2014), representando $97 \%$ de todos os camarões coletados. Esta espécie pode ser encontrada até os $118 \mathrm{~m}$ de profundidade, com maiores abundâncias até os $27 \mathrm{~m}$ (Rodrigues et al., 2015). No EB, por sua vez, Wolf (2014) identificou as maiores densidades aos 5 e $8 \mathrm{~m}$ de profundidade, enquanto Leite (2005) registrou entre os 10 e 20 m.

Rodrigues et al. (2015) verificaram a predominância de fêmeas em 13 dos 20 meses amostrados. Essa tendência também foi apresentada por Grabowski et al. (2014). O pico de maior porcentagem de fêmeas maduras observado por Grabowski et al. (2014) se deu nos meses de novembro e fevereiro (> 60 \%). Já Rodrigues et al. (2015), observou um pico no mês de outubro (89\%) e picos secundários (> $50 \%$ ) nos meses de fevereiro, novembro e dezembro.

No estudo desenvolvido por Wolf (2014), o camarão-santana (Pleoticus muelleri) foi a segunda espécie mais abundante na plataforma adjacente ao EB, ocorrendo em todas as profundidades amostradas $(5,8,11,14,17 \mathrm{~m})$.

Temporalmente, esta espécie apresentou elevadas abundâncias nos meses de inverno e no começo da primavera (outubro). Leite (2005) também observou maiores abundâncias desta espécie durante o inverno, nas profundidades 10,20 e $30 \mathrm{~m}$. A ocorrência de $P$. muelleri dentro do estuário foi registrada apenas por Branco (1998), na UP Entrada da Baía.

Em comparação à densidade de $X$. kroyeri e $P$. muelleri, o camarão barba-ruça (Artemesia longinaris) apresenta representatividade extremamente baixa na UP Marinha (Wolf, 2014). Apesar da abundância e constância menores, $A$. longinaris foi coletada durante os meses de inverno ocorrendo entre as profundidades 8 e 14 m (Wolf, 2014).

Aspectos biológicos (estrutura populacional, maturidade sexual, reprodução e recrutamento) de $P$. muelleri no EB foram avaliados por Wolf (2014). Para A. longinaris, o autor analisou apenas a estrutura populacional em virtude do baixo número de indivíduos coletados. Fêmeas de ambas as espécies apresentaram CC maior do que machos (Tabela $5 \mathrm{~b}$ ). Neste estudo poucas fêmeas reprodutivas de $P$. muelleri foram coletadas. No entanto, foi possível observar um aumento no número de fêmeas rudimentares e indivíduos juvenis nos meses de inverno, sinalizando o período de recrutamento da espécie.

Segundo Brandão et al. (2015), a presença de larvas de Pleoticus muelleri está associada a regiões de descarga continental (ex. desembocadura da Baía Babitonga), as quais são caracterizadas por altas concentrações de nutrientes e baixos valores de temperatura $\mathrm{e}$ salinidade. Já as larvas de $A$. longinaris foram registradas em três pontos da plataforma adjacente do EB (desembocadura do canal da Barra 
do Sul, do rio Saí-Guaçu e da Babitonga). As maiores densidades na Babitonga ocorrem no verão, demonstrando que tal época do ano é favorável à reprodução desta espécie (MarafonAlmeida et al., 2008).

A pesca dos camarões-rosa e branco é efetuada sobre seus dois estratos populacionais: a) juvenis e pré-adultos, pela pesca artesanal, em áreas estuarinas e; b) adultos, pela pesca industrial e artesanal, na plataforma (D'Incao et al., 2002, Serafini, 2012). Segundo Boos et al. (2016) a exploração de juvenis e adultos prejudica o fechamento de seu ciclo de vida e é seu principal fator de decréscimo em termos de abundância.

Dentro da Baía Babitonga a captura de camarões ocorre por meio do uso da rede de caceio e o gerival (Serafini, 2012). Outros petrechos de pesca tais como o "aviãozinho" são utilizados nas capturas de camarões realizadas na unidade de planejamento Linguado-Barra do Sul. Schmitt (2015) realizou um estudo na área de pesca utilizada pelos pescadores de Barra do Sul, identificando a dominância de $F$. brasiliensis neste local. Segundo a autora, esta espécie foi capturada em todas as fases lunares, com maior abundância na lua cheia, corroborando o relato dos pescadores. Apesar da exploração de $F$. brasiliensis, apenas $F$. paulensis e L. schmitti possuem um defeso específico dentro da Baía Babitonga (Portaria IBAMA $\left.\mathrm{n}^{\mathrm{o}} 70 / 2003\right)$ que proíbe sua captura no período de $1^{\circ}$ de novembro à 31 de janeiro.

Em alto mar, a pesca de camarões é feita com o arrasto (simples ou duplo) pela frota artesanal e industrial, sendo as principais espécies alvo, os camarões sete-barbas, santana e barba-ruça e indivíduos adultos do rosa e branco (Dias-Neto, 2011b; Serafini, 2012) .

A IN IBAMA $n^{0}{ }^{0} 89 / 2008$ estabelece o período de defeso dos camarões-rosa, camarão -sete-barbas, camarão-branco, camarãosantana ou vermelho e camarão-barba-ruça, proibindo a pescaria entre $1^{\circ}$ de março e 31 de maio. Apesar de contemplar várias espécies, a referida IN é compatível apenas com o período de recrutamento do camarão-sete-barbas (Grabowski, 2012; Grabowski et al., 2016) e do camarão-branco (Wolf, 2014). No entanto, $X$. kroyeri apresenta um padrão de reprodução contínuo, com mais de um pico de recrutamento de juvenis ao longo do ano (Grabowski et al., 2016), situação que dificulta a proteção integral dos recrutas a partir do estabelecimento de períodos de defeso (Rodrigues et al., 2015).

A pesca de arrasto empregada na captura de camarões em águas oceânicas é considerada um dos métodos mais eficazes haja vista o alto poder de captura e baixa seletividade. Em contrapartida, é apontado como o mais predatório e, portanto, danoso à biodiversidade e ao meio ambiente aquático (Dias-Neto, 2011b). Branco et al. (2015) identificaram a diversidade de fauna habitante de áreas utilizadas para pescaria de camarão-sete-barbas em Santa Catarina. O estudo, realizado na Unidade de Planejamento Marinha (município de Balneário Barra do Sul), registrou 133 espécies (crustáceos, peixes, equinodermos, moluscos e cnidários), das quais 42 foram muito frequentes. Ou seja, estas espécies muito frequentes mesmo não sendo o alvo, são comumente capturadas como fauna acompanhante na pescaria do camarão-sete-barbas.

\section{Considerações finais}

Estudos sobre a carcinofauna de importância comercial no Ecossistema Babitonga são relativamente recentes, ganhando maior expressão a partir de 2005.

A maioria dos trabalhos foi realizada envolvendo mais de uma instituição, evidenciando o quão positivas e necessárias são as parcerias interinstitucionais para a geração do conhecimento científico.

Ficou evidente nesta revisão a escassez de trabalhos com réplicas temporais, a maior parte deles com duração inferior a um ano (muitos com amostragem pontual). Normalmente a maior limitação para a realização de projetos de médio e longo prazo está atrelada à falta de recursos financeiros. Assim, se faz necessária a criação de instrumentos legais que incentivem e viabilizem o monitoramento contínuo dos recursos pesqueiros explorados no 
EB. Também é crucial a integração de pesquisadores e instituições de forma a promover o planejamento de futuros trabalhos optando pela utilização de protocolos de coleta já estabelecidos que nortearão a construção do conhecimento com foco nas lacunas ainda existentes.

Além disso, o emprego de avaliações em múltiplas escalas espaciais e temporais permitirá compreender, de forma integrada, a relação destas espécies com fatores bióticos, abióticos e antrópicos no EB, haja vista que distintos processos ecológicos podem atuar em diferentes escalas espaço-temporais.

Nesse contexto podemos também citar a necessidade de intensificar ações de monitoramento de desembarque pesqueiro para todas as espécies abordadas nesta revisão. Outra questão preocupante é a inexistência de um banco de dados unificado, no qual os cientistas possam inserir as informações geradas de maneira colaborativa e organizada. Ainda no escopo do monitoramento, destacamos a importância da inclusão de outros parâmetros biológicos (incluindo sexo, estágio de desenvolvimento e, biometria) além dos clássicos descritores populacionais (densidade/abundância e, biomassa) nos programas de monitoramento exigidos pelos órgãos ambientais que licenciam os empreendimentos no EB. Atualmente existe uma proposta do IBAMA para a unificação dos trabalhos de monitoramento ambiental dos terminais portuários por este órgão licenciados. As recomendações até aqui apresentadas vão ao encontro desta iniciativa que deve ser encorajada e apoiada.

Mais especificamente cabe destacar à carência de estudos bioecológicos sobre o siri C. sapidus e a necessidade de avaliar a distribuição espacial do siri exótico Charybdis hellerii no $\mathrm{EB}$, uma vez que sua presença representa uma ameaça às espécies nativas de siris $(C$. $d a$ nae e $C$. sapidus). Outras ações recomendadas para a conservação dos siris incluem: propostas de áreas de exclusão de pesca em regiões de trânsito de fêmeas ovígeras para a desova (barras e canais de ligação entre estuário e região costeira), incentivo a tecnologias de pesca seletivas (permitindo o descarte de indivíduos sem interesse comercial e/ou de subsistência) e, identificação de picos de reprodução e desova, que permitam identificar a necessidade de implementação de períodos de defeso.

Não existe um programa de estudos padronizado e contínuo para o caranguejo-uçá em qualquer nível de governo, mesmo onde a pesca é mais severa.

Neste caso, recomenda-se a adoção do protocolo de amostragem elaborado por Pinheiro \& Almeida (2015), para orientar ações de pesquisa e monitoramento da espécie. O EB se encontra muito próximo ao limite austral de ocorrência dos manguezais no Atlântico Sudoeste. Desta forma representa o limite de ocorrência de espécies diretamente associadas a este ecossistema, como é o caso de Ucides cordatus. Por isso se faz necessária a adoção de medidas que visem a conservação dos manguezais do EB, que dentre outros serviços ambientais, proveem a manutenção de $U$. cordatus. Considerando a importância socioeconômica deste recurso, é importante o direcionamento de pesquisas futuras que busquem quantificar o número de pessoas/famílias envolvidas na cadeia produtiva do caranguejo-uçá.

Sobre os camarões é importante citar que pouco se conhece sobre algumas espécies como, por exemplo, o camarão-santana (Pleoticus muelleri). Portanto é essencial o desenvolvimento de estudos que considerem aspectos de sua bioecologia e a interação da espécie com os sistemas pesqueiros artesanal e industrial a fim de gerar subsídios à gestão adequada deste recurso.

Com relação ao camarão-sete-barbas (Xiphopenaeus kroyeri) podemos considerar a dificuldade de proteção integral do recrutamento e o alto índice de fauna acompanhante capturada em pescarias de arrasto como as principais ameaças à conservação dos estoques e da qualidade do ecossistema. Nesse sentido deve-se incentivar a utilização de artefatos de pesca mais seletivos. Já para as espécies camarão-rosa ( $F$. paulensis e $F$. brasiliensis), santana (Pleoticus muelleri) e barba-ruça (Artemesia longinaris) é necessário avaliar o 
período de defeso, uma vez que este não se sobrepõe ao período de recrutamento destas espécies.

Branco (1998) foi o único autor que registrou o camarão-branco na porção interna da Baía Babitonga. Desta forma, é recomendável que se desenvolvam mais trabalhos direcionados à espécie, a fim de compreender sua distribuição espaço-temporal dentro deste estuário.

Por fim, destacamos a importância socioecológica da carcinofauna abordada nesta revisão. Assim, considera-se crucial a inclusão dos aspectos ecológicos, biológicos e econômicos da carcinofauna de importância comercial na elaboração de um Plano de Gestão para o Ecossistema Babitonga. O EB é responsável pela manutenção de diversos serviços ambientais e dá suporte para variados usos diretos e indiretos. Diante disto, é fundamental que a gestão deste território aconteça de forma integrada e participativa a fim de garantir a saúde ecossistêmica e a manutenção de suas funções ecológicas e sociais.

\section{Agradecimentos}

Os autores agradecem à Equipe Babitonga Ativa pela iniciativa e organização desta edição especial sobre o Ecossistema Babitonga.

\section{Referências Bibliográficas}

ANDRADE, L. S. FRAMESCHI, I. F. COSTA, R. C. CASTILHO, A. L. \& FRANSOZO, A. 2015. The assemblage composition and structure of swimming crabs (Portunoidea) in continental shelf Waters of southeastern Brazil. Journal Continental Shelf Research, 94: 8-16.

BABITONGA ATIVA. 2017. Diagnóstico socioambiental do Ecossistema Babitonga. São Francisco do Sul. 159p.

BASTOS, G. C. 2006. Atividade pesqueira na Baía da Babitonga. In CREMER, M. J., MORALES, P. R. D., OLIVEIRA, T. M. N. Diagnóstico ambiental da Baía da Babitonga. Univille, Joinville, Cap. 8: 200-244.

BOOS, H., BUCKUP, G. B., BUCKUP, L., ARAUJO, P. B., MAGALHÃES, C., ALMERÃO, M.
P., SANTOS, R. A. \& MANTELATTO, F. L. 2012. Checklist of the Crustacea from the State of Santa Catarina, Brazil. Checklist 8(6): 1020-1046.

BOOS, H., OLIVEIRA, M. M. \& DELFIN, R. 2010. Novos registros do siri exótico Charybdis hellerii (A. Milne-Edwards, 1867) (Crustacea, Portunidae), no litoral do Estado de Santa Catarina, Brasil. Revista CEPSUL - Biodiversidade e Conservação Marinha 1(1): 1-7.

BOOS, H., COSTA, R. C., SANTOS, R. A., NETO, J. D., RODRIGUES, E. S. RODRIGUES, L. F., D'INCAO, F., IVO, C. T. C. \& COELHO, P. A. 2016. Avaliação dos Camarões Peneídeos (Decapoda: Penaeidae). In PINHEIRO, M. \& BOOS, H. Livro vermelho dos crustáceos do Brasil: avaliação 2010-2014. Sociedade Brasileira de Carcinologia, Porto Alegre, RS, cap. 23: 300-317.

BRANCO, J. O. 1998. Proteção e Controle de Ecossistema Costeiro, Manguezal da Baía da Babitonga. Brasília, Edições Ibama. 140p.

BRANCO, J. O., JUNIOR, F. F. \& CHRISTOFFERSEN, M. L. 2015. Bycatch fauna of seabob shrimp trawl fisheries from Santa Catarina State, Southern Brazil. Biota Neotropica, 15(2): 1-14.

BRANDÃO, M. C., GARCIA, C A. E. \& FREIRE, A. S. 2015. Large-scale spatial variability of decapod and stomatopod larvae along the South Brazil Shelf. Continental Shelf Research, 107: 11-23

BRASIL. 1983. Portaria SUDEPE $\mathbf{n}^{\circ} 24$ de 26 de julho de 1983. Regulamenta a pesca do siri-azul (Callinectes danae e C. sapidus).

BRASIL. 2003. Portaria IBAMA $n^{\circ} 70$ de 30 de outubro de 2003. Institui o defeso do camarão-branco (Litopenaeus schmitti) e camarão-rosa (Farfantepenaeus paulensis) no interior da Baía Babitonga.

BRASIL. 2003. Portaria IBAMA ${ }^{\circ} 52$ de 30 de setembro de 2003. Institui o período de defeso do caranguejo-uçá (Ucides cordatus) nos estados do Espírito Santo, Rio de Janeiro, São Paulo, Paraná e Santa Catarina.

BRASIL. 2004. Instrução Normativa MMA No o5, de 21 de maio de 2004. Reconhece as espécies de invertebrados aquáticos e pei- 
xes ameaçados de extinção e sobreexplotados ou ameaçados de sobreexplotação.

BRASIL. 2008. Instrução Normativa IBAMA No 189, de 23 de setembro de 2008 . Estabelece o período de defeso dos camarõesrosa (Farfantepenaeus paulensis, $F$. brasiliensis, $F$. subtilis), camarão-sete-barbas (Xyphopenaeus kroyeri), camarão-branco (Litopenaeus schmitti), camarão-santana ou vermeho (Pleoticus mulleri) e camarão-barba -russa (Artemesia longinaris).

BRASIL. 2011. Instrução Normativa MPA/ MMA No 3 , de 28 de janeiro de 2011. Estabelece normas para o ordenamento da frota de arrasto na captura de camarões -sete-barbas.

COSTA, M. D. P., VIEIRA, J. V.,EGRES, A. G., LORENZI, L., BOOS-JUNIOR, H. \& CONCEIÇÃO, J. M. S. 2008. Análise da ocorrência de portunídeos (Crustacea, Decapoda) em três áreas de pesca na Baía da Babitonga (Santa Catarina,Brasil) e sua relação com os fatores bióticos e abióticos. Caderno de Iniciação Científica Univille.

CREMER, M. J., MORALES, P. R. D., OLIVEIRA, T. M. N. 2006. Diagnóstico ambiental da Baía da Babitonga. Joinville, Univille. 256p.

DE GRAVE, S., PENTCHEFF, N. D., AHYONG, S.T., CHAN, T.Y., CRANDALL, K. A., DWORSCHAK, P. C., FELDER, D. L., FELDMANN, R. M., FRANSEN, C. H. J. M., GOULDING, L. Y. D., LEMAITRE, R., LOW, M. E. Y., MARTIN, J. W., NG, P. Q. L., SCHWEITZER, C. E., TAN, S. H., TSHUDY, D. \& WETZER, R. 2009. A classification of living and fossil genera of decapoda crustaceans. Raffles Bulletin Of Zoology, 21: 1-109.

D'INCAO, F., VALENTINE, H. \& RODRIGUES, L. F. 2002. Avaliação da pesca de camarões nas regiões sudeste e sul do Brasil. 19551969. Atlântica, 24(2):103-116.

DIAS-NETO, J. 2011a. Proposta de plano nacional de gestão para o uso sustentável do caranguejo-uçá, do guaiamum e do siri-azul. Brasília. IBAMA. 156p.

DIAS-NETO, J. 2011b. Proposta de plano nacional de gestão para o uso sustentável de camarões marinhos do Brasil. Brasília. IBAMA. 242p.

DUMONT, L. F. C., D'INCAO, F., SANTOS, R. A., MALUCHE, S. \& RODRIGUES, L. F. 2007. Ovarian development of wild Pink prawn (Farfantepenaeus palensis) females in northern coast of Santa Catarina State, Brazil. Nauplius, 15(2): 65-71.

EGRES, A. G., LORENZI, L., CONCEIÇÃO, J. M. S., VIEIRA, J. V., COSTA, M. D. P. \& BOOSJUNIOR, H. 2009. A ocorrência de portunídeos (Crustacea, Decapoda) na Baía da Babitonga (Santa Catarina, Brasil), sua relação com o sedimento e as variáveis ambientais. Caderno de Iniciação Científica Univille.

GRABOWSKI R. C. 2012. Dinâmica populacional do camarão sete-barbas Xiphopenaeus kroyeri (Heller, 1862) (Crustacea: Decapoda) na Baía da Babitonga, estado de Santa Catarina. Botucatu [s.n.]. (Dissertação de Mestrado. Universidade Estadual Paulista, Instituto de Biociências de Botucatu).

GRABOWSKI, R. C., NEGREIROS-FRANSOZO, M. L. \& CASTILHO. A. L. 2016. Reprodutive ecology of the seabob shrimp Xiphopenaeus kroyeri (Heller, 1862) in a coastal área of Southern Brazil. Chinese Journal of Oceanology and Limnology, 34(1): 125-135.

GRABOWSKI, R. C., SIMÕES, S. M. \& CASTILHO, A. L. 2014. Population structure, sex ratio and growth of the seabob shrimp Xiphopenaeus kroyeri (Decapoda, Penaeidae) from coastal Waters of southern Brazil. Journal Zookeys, 457: 253-269.

LEITE, R. L. 2005. Variação espaço temporal da megafauna bentônica na plataforma rasa do norte de Santa Catarina, Brasil. São Francisco do Sul. 47 p. (Monografia da Graduação. Universidade da Região de Joinville - Univille).

MACHADO, I.F., DUMONT, L. F. C. \& D' INCAO, F. 2009. Stages of gonodal development and length at first maturity of wild females of White shrimp (Litopenaeus schimitti - Depodoa, Penaeidae) in Southern Brazil. Revista Atlantica, Rio Grande, 31(2): 169-175.

MARAFON-ALMEIDA, A. 2009. Distribuição espaço-temporal de decápodes meroplanctônicos na Baía da Babitonga, SC, Brasil. Curitiba. 62 p. (Dissertação de Mestrado. Universi- 
dade Federal do Paraná - UFPR).

MARAFON-ALMEIDA, A., SOUZA-CONCEIÇÃO, J. M. \& PANDOLFO, P. S. V. 2008. Distribuição e abundância de larvas de três espécies de Peneídeos (Decapoda) na plataforma continental interna adjacente à Baía da Babitonga, Sul do Brasil. PanamJAS, 3(3): 340-350.

MMA. 2007. Áreas Prioritárias para a Conservação, Uso Sustentável e repartição de Benefícios da Biodiversidade Brasileira: Atualização - Portaria MMA ${ }^{\circ}$ 09, 23 de janeiro de 2007. Ministério do Meio Ambiente. Brasília, Secretaria de Biodiversidade e Florestas. 30op.

ODUM, E. P. 1983. Ecologia. Rio de Janeiro, Guanabara. 434p.

OLIVERIA, T. M. N., TURECK, C. R., BASSFELD, J. C., TORRES, B. M. O. T., FARIA \& J. M., BRASIL, K. 2006. Integridade ambiental da Baía Babitonga: características físicoquímicas, microbiológicas e ecotoxicidade. In CREMER, M. J., MORALES, P. R. D., OLIVEIRA, T. M. N. Diagnóstico ambiental da Baía da Babitonga. Univille, Joinville, 256p.

PEREIRA, M. J. 2006. Estrutura populacional do gênero Callinectes na Baía da Babitonga, São Francisco do Sul, SC. (Dissertação de Mestrado. Universidade do Vale do Itajaí - Univali).

PEREIRA, M. J.; BRANCO, J. O.; CRISTOFFERSEN, M. L., FREITAS-JUNIOR, F., FRACASSO, H. A. A. \& PINHEIRO, T. C. 2009. Population biology of Callinectes danae and Callinectes sapidus (Crustacea: Brachyura: Portunidae) in the south-western Atlantic. Journal of the Marine Biological Association of the UK, 89(07): 1341-1351.

PEREIRA, R. C. \& SOARES-GOMES, A. 2002. Biologia Marinha. Rio de Janeiro, Interciência. 361p.

PINHEIRO, M. A. A. \& ALMEIDA, R. 2015. Monitoramento de populações do caranguejouçá, Ucides cordatus (Brachyura, Ucididae). In TURRA, A. \& DENADAI, M. R. Protocolos para o monitoramento de habitats bentônicos costeiros. Instituto Oceanográfico da Universidade de São Paulo, São Paulo, Cap. 10: 122133.

PINHEIRO, M. A. A., BOOS, H., REIGADA, A. L. D., RODRIGUES, E. S., ROCHA, S. S., HERE-
MAN, M. J. \& SOUZA, M. R. 2016. Avaliação dos caranguejos portunideos (Decapoda: Portunoidea: Ovalipidae, Polibidae e Portunidae. In PINHEIRO, M. \& BOOS, H. Livro vermelho dos crustáceos do Brasil: avaliação 20102014. Sociedade Brasileira de Carcinologia, Porto Alegre, RS, cap. 26: 337-365.

PRETO, A. L. 2009. Estrutura populacional do Camarão-rosa sobre-explotado Farfantepenaeus paulensis (Péres Fanfante, 1967) no litoral sul-sudeste brasileiro e seu significado para a conservação. São Carlos. (Tese de Doutorado. Universidade Federal de São Carlos - UFSCar).

RODRIGUES, L. R., BOOS, H. \& BRANCO, J. O. 2015. Biologia e pesca do camarão-setebarbas (Xiphopenaeus kroyeri, Heller 1862) no Balneário Barra do Sul, SC. Revista Cepsul Biodiversidade e Conservação Marinha 4: 4657.

RUPPERT, E. E., FOX, R. S. \& BARNES, R. D. 2005. Zoologia dos invertebrados: uma abordagem funcional-evolutiva. São Paulo, Rocco. 1927p. $7^{\circ}$ ed.

SABINO, F. N. A. 2014. Distribuiçãa espaçotemporal e dinâmica populacional do siri Callinectes danae Smith, 1869 (Decapoda: Portunidae) na região adjacente à Baía de Babitonga, Santa Catarina. Assis. 71 p. (Dissertação de Mestrado. Universidade Estadual Paulista - Unesp).

SCHMITT, J. 2015. Distribuição das espécies de camarões nas lagunas Linguado e Acaraí utilizando a técnica do gerival e a pesca artesanal de camarões em fases lunares na laguna Linguado, Santa Catarina, Brasil. São Francisco do Sul. 45 p. (Monografia de Graduação. Universidade da Região de Joinville Univille).

SERAFINI, T. Z. 2012. Limites e possibilidades para a construção da gestão compartilhada da pesca marinha-estuarina: Estudo de caso do sistema socioecológico pesqueiro da Baía da Babitonga-SC. Curitiba. 27op. (Tese de doutorado. Programa de Pós-Graduação em Meio Ambiente e Desenvolvimento. Universidade Federal do Paraná - UFPR).

SEVERINO-RODRIGUES, E., MUSIELLOFERNANDES, J., MOURA , A. A., BRANCO, 
G. M. P. \& CANÉO, V. O. C. 2012. Biologia reprodutiva de fêmeas de Callinectes danae (Decapoda, Portunidae) no Complexo Estuarino-Lagunar de Iguapê e Cananéia (SP). Boletim do Instituto de Pesca, 38(1): 31-41.

WOLF, M. R. 2014. Ecologia das populações e comunidade dos camarões Decapoda no litoral norte de Santa Catarina. Botucatu. 186p. (Dissertação de Mestrado. Instituto de Biociência de Botucatu, Universidade Estadual Paulista - Unesp).

WUNDERLICH, A. C., PINHEIRO, M. A. A. \& RODRIGUES, A. M. T. 2008. Biologia do caranguejo-uçá, Ucides cordatus (Crustacea: Decapoda: Brachyura) na Baía da Babitonga, Santa Catarina, Brasil. Revista Brasileira de Zoologia, 25(2): 188-198. 